ISSN: 1130-2887 - e-ISSN: 2340-4396

DOI: https://doi.org/10.14201/alh2017771745

\title{
PROXIMIDAD IDEOLÓGICA EN LAS ELECCIONES PRESIDENCIALES DE COSTA RICA, EL SALVADOR Y HONDURAS
}

\section{Ideological proximity in the presidential elections of Costa Rica, El Salvador and Honduras}

\author{
Juan Antonio RodRíguez ZEPEDA \\ Universidad de Salamanca, España \\ 凶jarz@usal.es
}

Patricia OTERO FELIPE

Universidad de Burgos, España

凶potero@ubu.es

Fecha de recepción: 5 de mayo de 2017

Fecha de aceptación y versión final: 11 de octubre de 2017

RESUMEN: En este artículo contrastamos la teoría del voto por proximidad ideológica en las más recientes elecciones presidenciales de tres países centroamericanos: Costa Rica, El Salvador y Honduras. Para tal efecto especificamos modelos Probit Mutinomiales Mixtos, a partir de los cuales encontramos que la cercanía ideológica tuvo un efecto relevante en dichas elecciones. La distancia entre votantes y candidatos afectó de manera diferente a estos últimos, dependiendo del contexto partidista en que competían. duras.

Palabras clave: voto por proximidad; elecciones presidenciales; Costa Rica; El Salvador; Hon-

ABSTRACT: In this article we test the theory of proximity voting in the most recent presidential elections of three Central American countries: Costa Rica, El Salvador and Honduras. For this purpose, we specified Mixed Mutinomial Probit models and found that ideological proximity had a relevant effect on voters' choices. Moreover, the ideological distance between those citizens and the candidates affected the latter differently, depending on the partisan context in which they were competing.

Key words: proximity voting; presidential elections; Costa Rica; El Salvador; Honduras. 
JUAN ANTONIO RODRÍGUEZ ZEPEDA Y PATRICIA OTERO FELIPE PROXIMIDAD IDEOLÓGICA EN LAS ELECCIONES PRESIDENCIALES DE COSTA RICA, EL SALVADOR Y HONDURAS

\section{INTRODUCCIÓN ${ }^{1}$}

La existencia de elecciones regulares, libres y justas es una de las piedras angulares de los regímenes democráticos modernos. Esta situación ha impulsado a los académicos y analistas de la política a prestar mucha atención a la investigación sobre las razones que subyacen detrás del voto de las personas. En consecuencia, el estudio del comportamiento electoral es uno de los ámbitos más relevantes del análisis politológico, en términos de desarrollo teórico y refinamiento metodológico, como atestigua la cantidad significativa de publicaciones que analizan las causas y consecuencias de los resultados electorales a nivel global. No obstante, a pesar de la abundante literatura publicada en esta área, aún quedan regiones del mundo donde no se han contrastado algunos de sus modelos teóricos.

En este artículo realizamos dos contribuciones al estudio sobre comportamiento electoral. La primera consiste en contrastar la teoría espacial del voto, usando los métodos estadísticos pertinentes. Para tal efecto, hemos especificado un modelo de regresión que permite estimar la existencia y magnitud del voto por proximidad ideológica en el contexto centroamericano. Además, centramos dicho análisis en tres países que han recibido poca atención en la literatura sobre el tema: Costa Rica, El Salvador y Honduras. En consecuencia, la selección de casos nos da la posibilidad de mostrar la incidencia del voto por proximidad en escenarios partidistas con diferencias importantes.

Los tres casos estudiados, pese a tratarse de sistemas de partidos estables y con niveles altos de institucionalización, han sufrido en los últimos años reconfiguraciones que evidencian la excepcionalidad de sus elecciones presidenciales recientes. Como se mostrará más adelante, esta transformación es clara en cuanto a su formato, con un incremento de los partidos políticos, así como respecto del tipo de candidaturas. La presencia de opciones diferentes a las tradicionales ha abierto el abanico ideológico a la ciudadanía, modificando la relevancia de la ideología en el voto, la cual ha sido tradicionalmente limitada en Honduras y Costa Rica. La entrada de nuevos competidores ha ocasionado, asimismo, un cambio en los tipos de candidatos presidenciales con la presencia de personas ajenas a la política. En este sentido, se trata de elecciones en las que, a pesar de haberse llevado a cabo en una situación económica estable, la popularidad del gobierno saliente ha sido muy baja.

A partir del análisis realizado, se muestra que los votantes de estos países sí han tomado en cuenta la cercanía ideológica en el momento de decidir a qué candidato otorgar su apoyo electoral. No obstante, encontramos que el efecto de la proximidad ideológica no es lineal, ni tiene la misma magnitud para todos los candidatos. Otro hallazgo relevante es que la oferta de candidatos que se presenta a los ciudadanos modera la relación entre distancia ideológica y voto. En los países analizados el número

1. Los autores agradecen los comentarios y las sugerencias de dos evaluadores anónimos de América Latina Hoy, Revista de Ciencias Sociales, a la primera versión de este artículo. Este trabajo se enmarca en el proyecto «Competición ideológica y sistema político: escenarios de estabilidad y escenarios de cambio» (CSO2015-63555-R, MINECO/FEDER), dirigido por la profesora Leticia M. Ruiz. 
JUAN ANTONIO RODRÍGUEZ ZEPEDA Y PATRICIA OTERO FELIPE

PROXIMIDAD IDEOLÓGICA EN LAS ELECCIONES PRESIDENCIALES DE COSTA RICA,

EL SALVADOR Y HONDURAS

de competidores y la polarización ideológica influyen en quién se beneficia de los votos que pierden algunos candidatos cuando los electores los consideran muy lejanos de sus posiciones ideológicas.

El artículo está estructurado de la siguiente manera. A continuación, se exponen los principales elementos teóricos propios del voto por proximidad, mencionando su aplicación empírica en la región latinoamericana. Después, se presentan los datos y el modelo estadístico utilizado para llevar a cabo el análisis empírico. Posteriormente se lleva a cabo la discusión de los resultados del análisis de las elecciones presidenciales de Costa Rica (2014), El Salvador (2014) y Honduras (2013). Finalmente, la quinta sección concluye retomando los principales hallazgos y sus implicaciones para los estudios del comportamiento electoral de la región.

\section{EL PAPEL DE LA PROXIMIDAD IDEOLÓGICA EN EL COMPORTAMIENTO ELECTORAL}

Desde el inicio del estudio sistemático de los fenómenos políticos, el papel de la ideología ha ocupado un lugar preponderante en la literatura académica. No obstante, la aproximación al análisis del papel de la ideología en el comportamiento electoral fue impulsada y transformada con la irrupción de la teoría de elección racional en la ciencia política. El modelo de voto espacial fue conceptualizado originalmente por Anthony Downs (1957), quien utilizó ideas de Harold Hotelling (1929) sobre la ventaja económica de la ubicación física en los negocios. El libro de Downs trajo a la literatura en ciencia política tres elementos muy relevantes. En primer lugar, el uso de la teoría de elección racional en el estudio de fenómenos políticos. Asimismo, acercó el análisis espacial a la investigación sobre la competencia electoral dentro de los sistemas democráticos. Finalmente, resaltó el papel de la incertidumbre en el estudio de los procesos electorales. Posteriormente, Enelow y Hinich (1984) formalizaron el modelo de voto espacial al sistematizar los avances teóricos alcanzados hasta ese momento.

Durante los últimos sesenta años el desarrollo teórico y metodológico de este modelo ha sido bastante prolífico. No obstante, el primero de estos aspectos es el que más atención ha recibido en la literatura de ciencia política². La versión original de este modelo está basada en la idea de proximidad. En términos simples, esto significa que mientras menor sea la distancia entre la posición de un votante y la del candidato con respecto a un tema de relevancia política, mayor será la probabilidad de que la persona vote por dicho partido. Este resultado tan directo está basado en dos asunciones. La primera es que las personas votan en función del candidato (partido) que les represente mayor utilidad. La segunda, es que la utilidad es una función decreciente de la distancia entre las posiciones del votante y el candidato 3 . Esta última ha sido cuestionada por

2. En la sección sobre datos y métodos tratamos el aspecto metodológico de este modelo de voto.

3. La condición necesaria para que este segundo supuesto se cumpla es que tanto los votantes como los candidatos o partidos puedan ser ubicados en un punto de la escala ordinal que representa los temas relevantes electoralmente. 
algunos autores, quienes han señalado que, bajo este supuesto, los votantes tendrían que llevar a cabo cálculos que en la mayoría de los casos exceden sus capacidades y/o nivel de interés. Por tanto, para solventar esta situación, Rabinowitz y MacDonald (1989) propusieron la vertiente direccional del modelo de voto espacial.

En el modelo direccional, el proceso de decisión electoral se construye a partir de dos elementos relacionados. Por un lado, la ubicación de los votantes con respecto a un punto neutral. Dicho de otro modo, que los ciudadanos eligen primero de qué lado están con respecto a un tema público y la intensidad del sentimiento que tienen con respecto al tema en cuestión. La diferencia sustancial es que en el modelo de voto por proximidad los candidatos más extremos tienden a ser penalizados electoralmente, mientras que en el modelo direccional los candidatos con posturas más vehementes pueden maximizar su apoyo electoral. Sin embargo, para evitar que este modelo predijera la elección de candidatos con posiciones extremas, Rabinowitz y MacDonald (1989) introdujeron la «región de aceptabilidad», incorporando al planteamiento original la idea de que los votantes descartarán candidatos a los que consideren demasiado radicales ${ }^{4}$.

Ahora bien, ¿cuál de los dos modelos ha tenido mayor soporte empírico? La respuesta a esta interrogante no ha sido proporcionada por la literatura de forma decisiva. Aunque varios estudios se han abocado a la tarea de dilucidar cuál de los dos modelos describe mejor la lógica de voto de los ciudadanos, ninguno ha ofrecido un veredicto claro. Para Lewis y King (1999), esta situación se debe a que los investigadores eligen contrastar los modelos respetando aquellas asunciones que favorecen a su modelo de preferencia. Por tanto, al hacer una revisión de los trabajos más recientes, la balanza tiende a decantarse por el modelo de proximidad. Asimismo, los resultados de estudios experimentales han favorecido a dicho modelo (Tomz y Van Houweling 2008; Lacy y Paolino 2010).

Por su parte, los trabajos basados en encuestas aplicadas en Europa han señalado que el voto por proximidad es más común (Fazekas y Méder 2013). Otros estudios han encontrado que el voto direccional es más prevalente en sistemas de partidos más polarizados, mientras que el voto por proximidad tiene mayor peso en sistemas con menor nivel de polarización (Pardos-Prado y Dinas 2010). En el ámbito latinoamericano, Boscán (2016) encontró evidencia que favorecía al modelo direccional, aunque no de forma

4. Los modelos de voto espaciales no se agotan en la dicotomía proximidad versus direccional. Hay otros dos que se han presentado para corregir las deficiencias de los dos modelos «puros». El primero, propuesto por B. GROFMAN (1985), señala que los votantes incluyen en sus decisiones de voto la incertidumbre que generan los candidatos respecto a la posibilidad de cumplir sus promesas de campaña. La propuesta original de A. Downs (1957) ya hacía patente que los ciudadanos basaban sus decisiones electorales en lo que consideraban que los candidatos podían lograr, no sólo en sus promesas de campaña. A partir de esta idea, O. KEDAR (2009) desarrolla el voto por compensación, en el que dentro de la decisión de a quién votar se tienen en cuenta las expectativas del ciudadano en la fase de formación de la política pública. La segunda aproximación es un modelo «mixto», que combina elementos de proximidad y direccionalidad. T. IVERSEN (1994) propuso una versión muy popular de este modelo al no estar convencido del lugar que juega la «región de aceptabilidad». 
contundente. En este trabajo nos adscribimos al modelo por proximidad, al considerar que este representa una prueba más estricta de la importancia de los modelos espaciales para explicar el comportamiento electoral en América Latina, tomando en consideración la relevancia que tiene la ideología en las decisiones de los votantes.

Bajo este orden de ideas, la relación entre ideología y voto ha sido una cuestión muy controvertida en el contexto latinoamericano. La tendencia dominante ha sido explicar el comportamiento electoral por otros motivos, dejando la cuestión posicional en un segundo plano, asumiendo que no existía o que era contingente. De hecho, el grueso del análisis electoral, tanto a nivel comparado como en estudios de un solo país, se ha centrado en otros elementos, tales como el impacto de la situación económica, el efecto del clientelismo, la influencia de la identidad partidista y de las campañas en la participación electoral, o en el voto a partidos y candidatos. Esta visión pesimista asume que en los países latinoamericanos no se cumple con uno de los principales requisitos de las democracias representativas: elegir a los candidatos y a los partidos que mejor representen las propias posiciones ideológicas y programáticas, poniendo en duda, por ende, la capacidad de rendición de cuentas de los ciudadanos ante sus gobernantes.

Esta caracterización se ha ido matizando en parte con diferente tipo de evidencia, la cual ha mostrado que el constructo izquierda-derecha es un instrumento válido para reducir la multidimensionalidad del espacio político, así como para estructurar la competencia partidista en la región (Alcántara 2004; Rosas 2005). Otros trabajos han resaltado la validez de las etiquetas izquierda y derecha para la ubicación de los ciudadanos, aunque su significado varíe entre países e individuos (Colomer y Escatel 2005). La literatura reciente también ha puesto en entredicho la imagen tradicional sobre la prevalencia de los vínculos clientelar y carismático, poco compatibles con el ideológico, siendo plausible la convivencia de ambas estrategias de vinculación hacia el electorado al interior de un mismo partido (Luna 2014).

Ahora, los trabajos que han abordado desde un punto de vista comparado la relación entre ideología y comportamiento electoral han destacado su relevancia en países con altos niveles de institucionalización partidista, tales como El Salvador, Uruguay o Chile, mientras que sistemáticamente se ha negado en los sistemas más fluidos y con tradición más clientelar o personalista. En cualquier caso, la inclusión de la ideología en los modelos explicativos del voto ha sido muy diferente desde el punto de vista metodológico. En la mayoría de casos se ha establecido la importancia del voto ideológico a través de métodos indirectos, pero son pocos los trabajos que han especificado la incidencia del voto por proximidad con un modelo estadístico adecuado. Algunos estudios, por ejemplo, han incluido la ubicación ideológica o las preferencias en políticas públicas como variable predictora del voto a los partidos y candidatos de izquierda o derecha (Baker y Green 2011); han utilizado correlaciones para contrastar las posiciones ideológicas y programáticas de los partidos y los votantes (Luna y Zechmeister 2005); han relacionado autoubicación ideológica y voto presidencial (Seligson 2007), y han establecido las probabilidades de votar por un partido al variar la ubicación ideológica del elector (Mainwaring y Torcal 2005). 
En este sentido, son escasos los análisis del voto posicional en la región que cuenten con una estimación directa. En un trabajo anterior mostramos en qué tipo de elecciones (legislativas y presidenciales) los partidos atraían al elector más próximo ideológicamente y cuáles perdían votantes downsianos. Así, aunque el promedio de la proporción regional no era muy alto $(35 \%)$, se puso de manifiesto la enorme variedad entre la fortaleza del voto por proximidad en la región (Otero y Rodríguez 2014). Por su parte, Baker y Greene (2015) hallaron la existencia de voto posicional en buena parte de los países latinoamericanos, a partir de la predicción de la ubicación ideológica del candidato, considerando la posición en políticas económicas de los electores.

Estos aportes ponen de manifiesto que existen requisitos contextuales que facilitarían o impedirían la presencia del voto por proximidad. Por ejemplo, en los sistemas de partidos en los que las etiquetas partidistas están bien definidas, sin ambigüedad en las posiciones ideológicas y programáticas, la competencia por el voto estará en mayor medida estructurada ideológicamente, favoreciendo el voto por proximidad. Además, la relevancia de la dimensión ideológica y la diferencia de los partidos en competición, tradicionalmente medida a través de la polarización del sistema de partidos, es otro elemento a tener en cuenta para la existencia del voto por proximidad. A estos aspectos se uniría una fragmentación limitada del sistema de partidos, dado que el menor número de competidores políticos incentiva la consideración de la cercanía en términos de derecha e izquierda en las decisiones electorales.

Por otro lado, habría tres elementos que inhibirían la presencia de voto por proximidad. Primero, la entrada y salida de partidos del escenario partidista, al hacer más difícil conocer las posiciones defendidas de los candidatos y partidos. En segundo lugar, la presencia de outsiders, dado que la evaluación del elector es menos accesible ante la presencia de líderes y candidatos que provienen de fuera de las estructuras partidistas tradicionales. Finalmente, los incentivos para votar estratégicamente, ya que en aquellos países donde no existe la segunda vuelta en elecciones presidenciales -como en Honduras- es más factible que algunos votantes abandonen su primera preferencia si esta no tiene opciones de victoria. Siguiendo las aportaciones teóricas discutidas, el voto por proximidad será más viable en contextos donde la ideología estructure la competencia partidista, exista una baja fragmentación, así como una volatilidad y fluidez limitadas. En este sentido, las elecciones de los tres países centroamericanos que se analizan a continuación son una buena oportunidad para comprobar hasta qué punto la proximidad ideológica es relevante en el voto.

\section{DATOS Y MODELO EMPÍRICO}

Para poder contrastar las expectativas teóricas del voto por proximidad hemos usado un modelo de regresión Probit Multinomial Mixto (PMM). Dado que este ha sido utilizado en estudios empíricos sobre voto espacial, permite reflejar la estructura de decisión que enfrentan los individuos al ejercer su voto (Álvarez y Nagler 1998; Quinn, 
JUAN ANTONIO RODRÍGUEZ ZEPEDA Y PATRICIA OTERO FELIPE

PROXIMIDAD IDEOLÓGICA EN LAS ELECCIONES PRESIDENCIALES DE COSTA RICA,

EL SALVADOR Y HONDURAS

Martin y Whitford 1999)5. El elemento esencial de la especificación de estos modelos radica en que el fenómeno analizado es operacionalizado como una variable categórica nominal. En este caso, las categorías $(j)$ corresponden a los candidatos. Desde la perspectiva de elección racional, las personas deben decidir entre las diferentes opciones, otorgando su voto a aquella que les representa más utilidad esperada. Por consiguiente, el modelo de utilidad queda especificado de la siguiente manera (Train 2009):

$$
U_{i j}=\mathrm{x}_{\mathrm{i}} \boldsymbol{\beta}_{\mathrm{j}}{ }^{\prime}+z_{\mathrm{ij}} \boldsymbol{\gamma}^{\prime}+\boldsymbol{\varepsilon}_{\mathrm{ij}}, j=1, \ldots, J \operatorname{con} \boldsymbol{\varepsilon}_{\mathrm{ij}} \sim N(0, \Sigma)
$$

En este encontramos dos tipos de predictores: aquellos que tienen variación entre las opciones y los individuos $\left(\mathrm{z}_{\mathrm{ij}}\right)$, por un lado, y aquellos que solo varían entre los individuos $\left(\mathrm{x}_{\mathrm{i}}\right)$, por el otro. Entre los primeros se encuentran las evaluaciones retrospectivas que las personas hacen sobre la economía, ya que dichas opiniones no son una característica inherente a las opciones que son objeto de la decisión electoral. Por otro lado, la distancia ideológica del votante con respecto a cada uno de los candidatos sí presenta variación entre candidatos y entre personas. El componente de la utilidad individual que no es observable es incluido como un término estocástico $\left(\varepsilon_{\mathrm{iji}}\right)^{6}$.

Otro elemento toral de la especificación de los modelos de voto por proximidad atañe a la medición de la distancia entre las posiciones de los votantes y los candidatos. En dicha literatura se han utilizado principalmente la distancia euclidiana cuadrática, o la City Block. Si $i_{k}$ denota la posición ideológica de un individuo y $j_{k}$ la de un candidato para un espacio con $n>0$ dimensiones, la primera de las distancias estaría definida por la fórmula $\sum\left(i_{k}-j_{k}\right)^{2}$ y la segunda por $\sum\left|i_{k}-j_{k}\right|$. En términos empíricos no existe una diferencia importante entre ambas métricas (Westholm 1997), aunque es importante considerar que sí representan concepciones diferentes en cuanto a la función de pérdida de utilidad (Thurner 2000). Nosotros usamos la segunda de ellas, dado que consideramos que representa una regla de decisión más simple y cercana al proceso de decisión de la mayoría de los votantes ${ }^{7}$.

Los datos utilizados para llevar a cabo el análisis empírico provienen del Barómetro de las Américas (LAPOP) y del Proyecto de Élites Parlamentarias de América Latina (PELA). Todas las encuestas de LAPOP fueron llevadas a cabo en el año 2014, después de las elecciones presidenciales de Costa Rica, El Salvador y Honduras. La variable dependiente fue construida a partir de la pregunta de LAPOP concerniente al recuerdo de voto en las pasadas elecciones presidenciales ${ }^{8}$. La primera variable independiente es

5. La discusión sobre la idoneidad de este modelo se encuentra en un apéndice que puede ser solicitado a los autores.

6. En los modelos Probit se asume que el componente estocástico tiene una distribución multivariante normal con media cero y es posible especificar la matriz de varianzas y covarianzas de diferentes formas, para reflejar la relación entre las opciones de decisión.

7. También estimamos los modelos usando la medida euclidiana cuadrática y los resultados fueron prácticamente iguales.

8. Esta pregunta hace referencia a la primera vuelta de las elecciones. No fueron considerados en el análisis aquellos encuestados que no votaron, quienes no desearon contestar la pregunta y los que no 
la distancia (City Block) ideológica entre los votantes y cada uno de los candidatos. Esta variable fue operacionalizada a partir de la autoubicación ideológica de los votantes en una escala entre 1 (muy de izquierdas) a 10 (muy de derechas). Por lo tanto, el rango teórico de esta variable es de cero a nueve. Asimismo, la posición de los candidatos corresponde a la media de la ubicación que dieron a los candidatos los diputados entrevistados en las encuestas de PELA en cada uno de los países9. A pesar de no contar con datos sobre las posiciones de votantes y candidatos en otros temas de relevancia política, el uso de la dimensión ideológica permite que nuestro trabajo mantenga un diálogo con la literatura sobre voto espacial, donde se ha privilegiado el análisis de las posiciones en la dimensión izquierda-derecha. Además, las etiquetas ideológicas han sido concebidas desde los primeros estudios sobre comportamiento electoral, como indicadores de los paquetes de políticas públicas que ofrecen los partidos y como predictores de las posiciones de los votantes en diferentes temas públicos.

Los modelos también incluyeron variables independientes de control. La primera corresponde a las evaluaciones sociotrópicas del estado de la economía. Este predictor fue incluido dada su importancia teórica y empírica en los estudios sobre comportamiento electoral en América Latina. Se construyó a partir de la pregunta sobre la evaluación que hicieron los encuestados sobre la economía del país con respecto al año anterior, a partir de tres posibles valores: -1 (peor), 0 (igual) y 1 (mejor) ${ }^{10}$. Igualmente, incluimos tres predictores correspondientes a características demográficas de los votantes. El primero es el sexo, operacionalizado de forma dicotómica $(0=$ hombre, $1=$ mujer), y las otras dos variables independientes son la edad de las personas, así como sus años de educación formal ${ }^{11}$.

Para llevar a cabo la discusión de los resultados del análisis estadístico es necesario recordar antes algunas características particulares de los modelos de regresión que hemos especificado. Al aplicar los test de Hausman-McFadden y Small-Hsiao (Long y Freese 2014), determinamos que solo en el caso de Honduras se violala condición de independencia de alternativas irrelevantes (IAI), por lo que se estimó el modelo permitiendo la correlación entre los términos de error, así como que estos tuvieran varianzas heterocedásticas ${ }^{12}$. Otro elemento esencial es que, para poder estimar estos modelos, es necesario que una

recordaron por quién votaron. En todos los casos los candidatos considerados representan casi el $100 \%$ de los votos emitidos. En los tres casos una proporción mayor de los encuestados reportó haber votado por el ganador. Esta es una situación común en las encuestas donde se pregunta a las personas sobre su recuerdo de voto y las posibles soluciones no están exentas de sesgos, véase L. R. ATKESON (1999).

9. Véase en el Apéndice del texto las posiciones ideológicas medias de cada candidato.

10. Solo hemos incluido la evaluación sociotrópica porque es la que tuvo un efecto estadísticamente significativo en los modelos. Esto es común en estudios sobre voto económico (D. D. KINDER y D. R. KIEWIET 1979).

11. Para el caso de Honduras se incluyó como control adicional la variable urbano/rural. Esta variable no fue significativa en los modelos de los otros países estudiados. Los test de razones de verosimilitud tampoco apoyaron su inclusión.

12. Esta situación también puede ser indicativa de que algunos hondureños sí votaron de forma estratégica al abandonar su opción más cercana ideológicamente para votar por una opción más viable. 
JUAN ANTONIO RODRÍGUEZ ZEPEDA Y PATRICIA OTERO FELIPE

PROXIMIDAD IDEOLÓGICA EN LAS ELECCIONES PRESIDENCIALES DE COSTA RICA,

EL SALVADOR Y HONDURAS

de las opciones (candidatos) de elección sirva de base para comparar el efecto de los coeficientes. Esta situación es equiparable al caso de los modelos Probit, con variable dependiente dicotómica, donde generalmente se operacionaliza dicha variable a partir de los valores 0 y 1 (ausencia/presencia de un fenómeno). El primero sirve de base para la comparación de los coeficientes.

Dentro del análisis de resultados presentamos tres gráficos de probabilidades estimadas, derivados de los modelos especificados para cada elección. Primero, para analizar el efecto de la distancia ideológica mostramos dos gráficos. Estos corresponden a las probabilidades estimadas de votar por cada candidato, al variar la distancia ideológica entre los ciudadanos y uno de ellos. El resto de las variables permanece constante. Así, seleccionamos los candidatos que obtuvieron el primer y segundo lugar en las preferencias de los votantes. De esta manera mostramos el efecto de la diferencia en posición ideológica en las dos opciones electorales más relevantes ${ }^{13}$. Por último, el tercer gráfico corresponde a los tres escenarios correspondientes a las evaluaciones económicas, y el resto de las variables independientes permanecen fijas en su valor medio ${ }^{14}$.

\section{ANÁLISIS EMPÍRICO}

\section{IV.1. Costa Rica (2014)}

Durante décadas, el sistema de partidos de Costa Rica fue bipolar y estable. El Partido de la Liberación Nacional (PLN) y el Partido Unidad Social Cristiana (PUSC) fueron las fuerzas políticas ampliamente dominantes durante los años ochenta y noventa, a pesar de la presencia de terceros partidos con poca relevancia electoral. Este bipartidismo centrista fue escasamente polarizado en términos ideológicos. PLN y PUSC se alternaron en el gobierno mostrando una progresiva convergencia en las políticas llevadas a cabo. Así, el triunfo en las elecciones presidenciales tenía más que ver con la capacidad de movilizar al electorado que con la identificación partidaria o la diferenciación en el programa (Zoco 2006).

Esta situación se mantuvo con pocos cambios hasta las elecciones de 1998. Desde esa fecha se evidenciaron los primeros síntomas del desalineamiento electoral, con un incremento de la volatilidad legislativa y presidencial, así como un descenso en los niveles de participación (Sánchez 2003). Sin embargo, fue en las elecciones de 2002, y especialmente en las siguientes, cuando se materializó la recomposición del sistema de partidos. Esta tuvo su máxima expresión en el desplome electoral del PUSC y el ascenso del Partido Acción Ciudadana (PAC) a la segunda posición. La erosión de las lealtades partidarias provocó el desplazamiento del tradicional eje centro-derecha (PLN-PUSC) al centro-izquierda (PLN-PAC), así como el surgimiento y consolidación de terceras fuerzas.

El análisis estadístico fue realizado en stata 13. Los resultados de los test pueden ser proporcionados por los autores.

13. Las probabilidades estimadas en los otros escenarios pueden ser solicitadas a los autores.

14. En el Apéndice del texto se presentan los descriptivos de las variables incluidas. 
JUAN ANTONIO RODRÍGUEZ ZEPEDA Y PATRICIA OTERO FELIPE PROXIMIDAD IDEOLÓGICA EN LAS ELECCIONES PRESIDENCIALES DE COSTA RICA, EL SALVADOR Y HONDURAS

Esto aumentó la fragmentación, alterando notablemente la dinámica parlamentaria. En este sentido, la presidencia de Laura Chinchilla (2010-2014) sufrió las consecuencias del gobierno divido al perder el PLN la mayoría parlamentaria en 2011.

\section{GRÁFICO I}

EvoluCión DEL SISTEMA DE PARTIDOS DE COSTA RICA (1982-2014) $)^{15}$

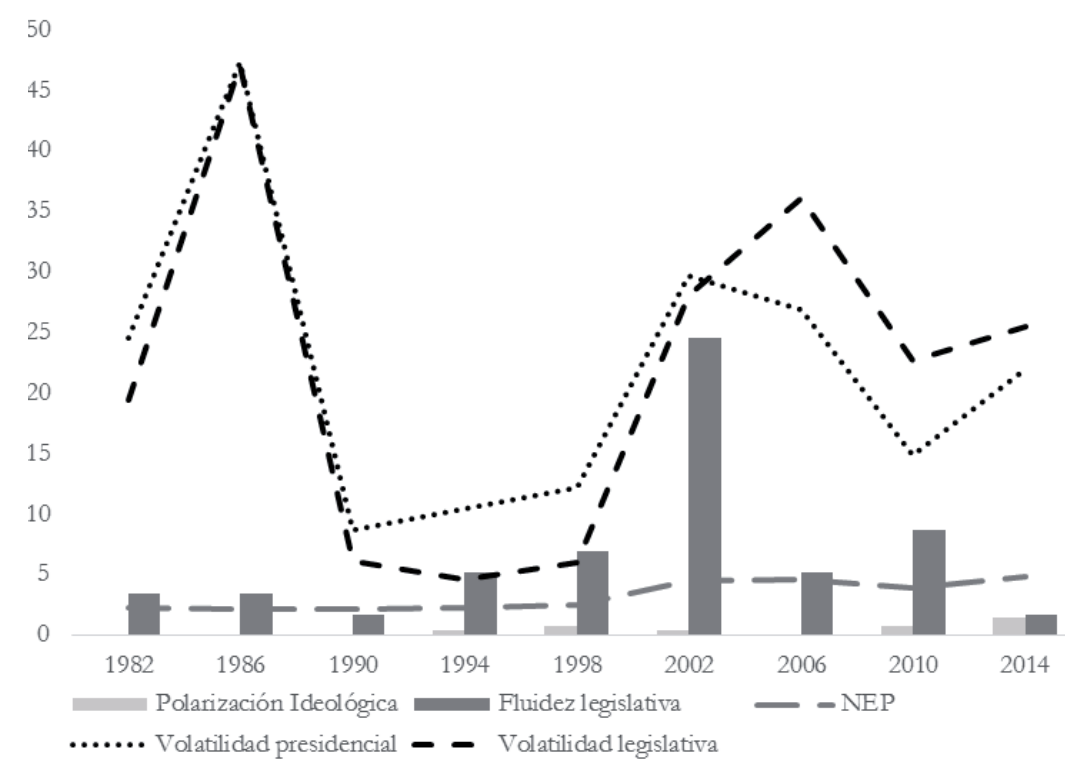

Fuente: Elaboración propia.

El proceso electoral del 2014 estuvo rodeado de bastante incertidumbre en cuanto al posible resultado. Como mostraron diferentes encuestas de opinión pública, que marcaban un alto número de indecisos durante la campaña, muchos decidieron su voto en los últimos días (Tremiño 2016) ${ }^{16}$. A pesar de una situación económica favorable en el país, Chinchilla terminaba su mandato con los índices más bajos de popularidad presidencial de los últimos años, fruto no solo del descontento ante su gestión, sino también del desgaste acumulado del partido tras ocho años en el Ejecutivo. En las elecciones presidenciales hubo cinco candidatos de diferente perfil ideológico y trayectoria política. El PLN se presentaba para ganar su tercera presidencia consecutiva con Johnny

15. Los índices han sido calculados a partir de los datos de PELA y el Observatorio de Instituciones Representativas (OIR) de la Universidad de Salamanca. Las fórmulas de los mismos pueden encontrarse en L. Ruiz Rodríguez y P. Otero FeliPe (2013).

16. En estas elecciones se eligieron únicamente diputados y presidente. 
Araya -alcalde de San José entre los años 1998 y 2013-. Araya era muy conocido entre los costarricenses, pero representaba el sector del partido opuesto a Óscar Arias, del que también provenía Chinchilla. De hecho, su campaña estuvo focalizada en sus propuestas como candidato, alejándose tanto del gobierno de su predecesora como del legado del PLN. El candidato del PAC fue el académico Luis Guillermo Solís, poco conocido entre los electores dada su corta historia dentro del partido, al que se unió en 2008 luego de dejar el PLN. No obstante, en el transcurso de la campaña se posicionó como la opción moderada frente a los partidos tradicionales, atrayendo no solo a los indecisos, sino también a electores del PLN y del Frente Amplio (FA). Otto Guevara, fundador del Movimiento Libertario (ML), repetía como candidato del partido más a la derecha del sistema. En estas elecciones, la novedad provino del impulso que logró la candidatura del izquierdista José María Villalta, del partido minoritario FA, que había sido diputado en el periodo anterior. El PUSC presentó como candidato a Rodolfo Piza, tras la renuncia del vencedor de sus primarias. Los resultados fueron muy ajustados en la primera vuelta, quedando Solís en primer lugar (30,6\%) frente a Araya (29,7\%). Por detrás quedaron Villalta (17,3\%), Guevara (11,3\%) y Piza (6,02\%). Al no lograr ninguno el $40 \%$ de los votos, se celebró una segunda el 6 de abril en la que se confirmó el triunfo histórico de un partido no tradicional en los comicios presidenciales ${ }^{17}$.

Los resultados de los modelos PMM para esta elección se encuentran en la Tabla I. A partir de los coeficientes del modelo estimado, en el que se ha tomado como base para el contraste a $A_{\text {raya }}{ }^{18}$, podemos observar que la distancia ideológica entre los votantes y los candidatos tiene un efecto significativo y en el sentido (negativo) esperado. Es decir, la probabilidad de votar por el candidato aumenta entre menor sea la distancia ideológica del ciudadano con aquel. Al igual que en otros modelos de regresión no lineales, no es posible conocer la magnitud del efecto de los predictores en la variable dependiente, a partir de los coeficientes de los modelos PMM. Por ello, es necesario estimar las probabilidades de selección de cada opción, tal y como muestran los Gráficos II y III. El primero presenta las probabilidades estimadas de votar a los candidatos presidenciales al variar la distancia ideológica entre los votantes y Luis Guillermo Solís, el candidato ganador. En este gráfico se observa que cada incremento en la distancia ideológica entre los votantes y Solís representa aproximadamente dos puntos porcentuales de disminución en la probabilidad de voto por él ${ }^{19}$. Estas disminuciones son capitalizadas principalmente por Johnny Araya (PLN) y, en segundo lugar, por Villalta (FA). En el Gráfico III se advierte que la tasa de disminución en la probabilidad estimada de voto por Araya tiene un patrón similar a la del gráfico anterior -el descenso es mayor al principio $(1,9 \%$ ) y después la tasa es ligeramente menor que la de Solís (alrededor del 1,5\%)-. En este escenario, son los candidatos de centro-izquierda los que se ven

17. Solís recibió un respaldo del $77 \%$ frente al 22,1\% de Araya, quien desistió de participar a pocas semanas de celebrarse la elección.

18. En los tres casos el candidato de referencia corresponde al del partido gobernante.

19. La disminución en la probabilidad de votos no es constante en ninguno de los casos debido a que no son modelos lineales. En este caso el descenso varía entre el 1,79 y el 2,06\%. 
JUAN ANTONIO RODRÍGUEZ ZEPEDA Y PATRICIA OTERO FELIPE PROXIMIDAD IDEOLÓGICA EN LAS ELECCIONES PRESIDENCIALES DE COSTA RICA, EL SALVADOR Y HONDURAS

\section{TABLA I}

Modelo Probit Multinomial Mixto: Costa Rica 2014

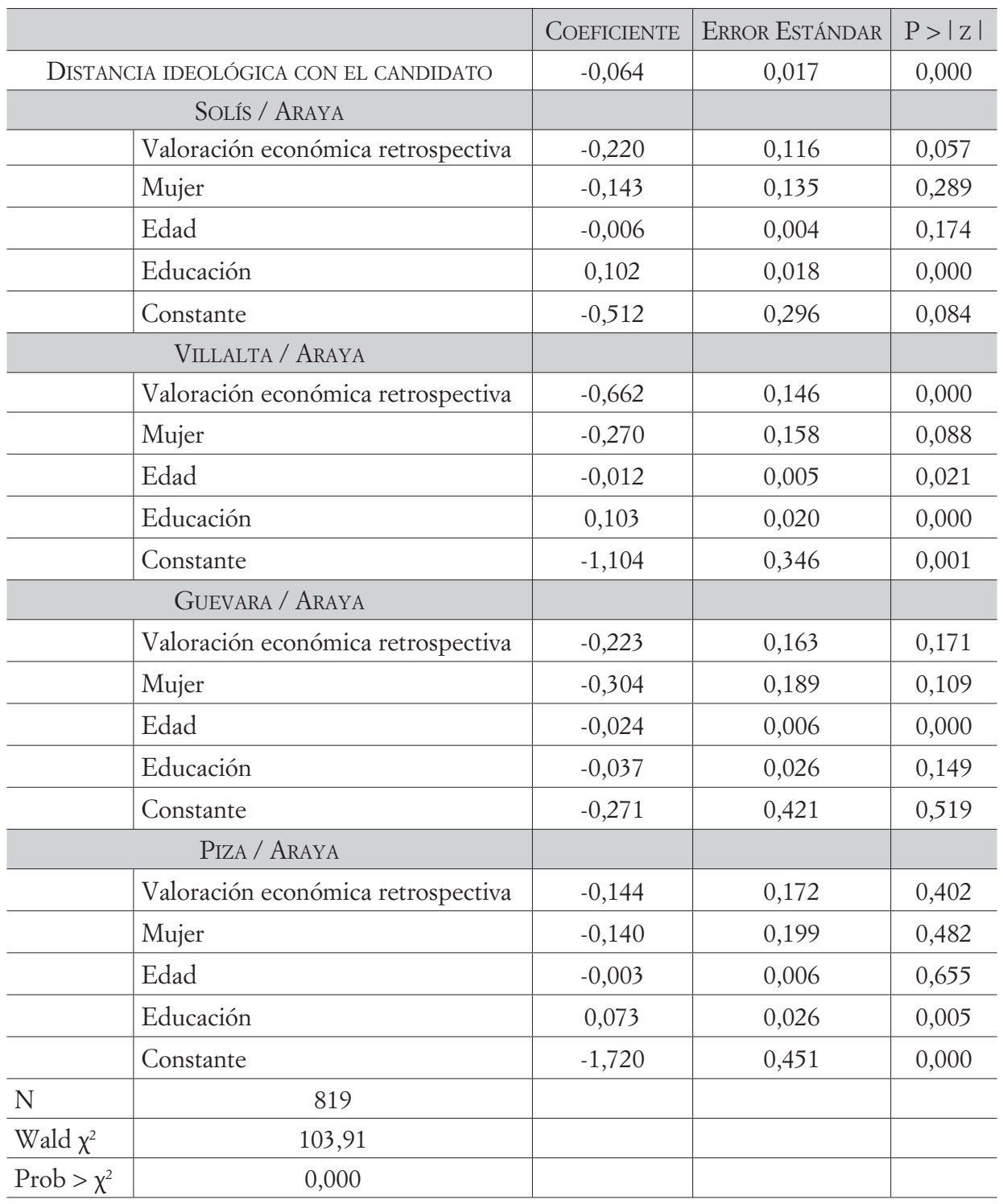

Nota: Araya es la alternativa que normaliza la localización. Piza es la alternativa que normaliza la escala. Fuente: Elaboración propia. 
JUAN ANTONIO RODRÍGUEZ ZEPEDA Y PATRICIA OTERO FELIPE

PROXIMIDAD IDEOLÓGICA EN LAS ELECCIONES PRESIDENCIALES DE COSTA RICA,

EL SALVADOR Y HONDURAS

beneficiados por dicha disminución: Solís y Villalta. Si bien este modelo predice principalmente el voto por el primero, es posible observar que la distancia ideológica sí fue un factor importante en las decisiones de voto en estos comicios.

GRÁFICO II

DisTANCIA IDEOLÓGICA CON LUIS GUILLERMO SOLÍS Y PROBABILIDAD DE VOTO

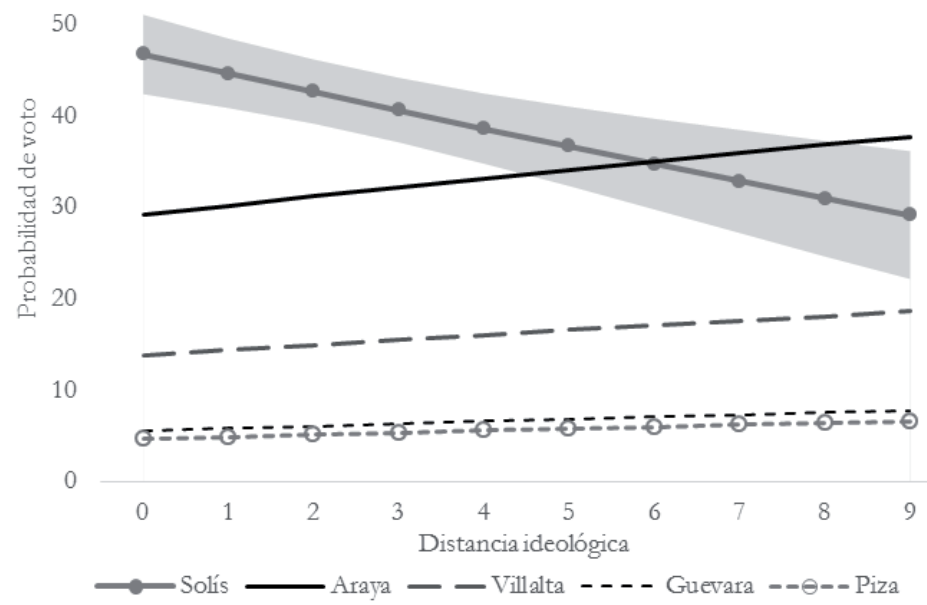

Fuente: Elaboración propia.

GRÁFICO III

DiSTANCIA IDEOLÓGICA CON JOHNNY ARAYA Y PROBABILIDAD DE VOTO

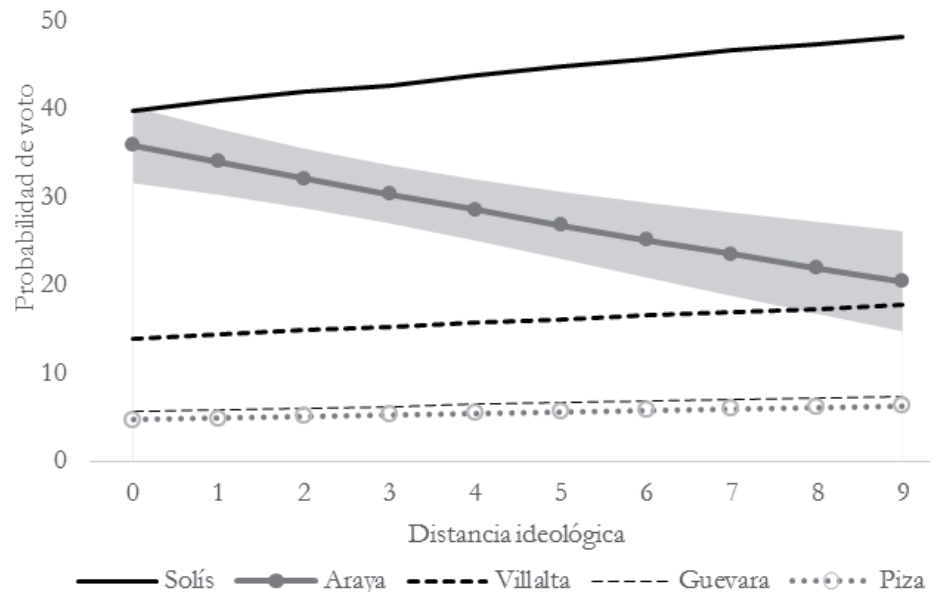

Fuente: Elaboración propia. 
Por último, el Gráfico IV muestra que las evaluaciones económicas también tuvieron un efecto en la posibilidad de selección de los candidatos. Entre los ciudadanos que consideran que la economía del país había empeorado, Villalta obtiene un claro tercer lugar en las probabilidades estimadas de voto. En ninguno de los otros dos escenarios se presenta una situación similar. Al mismo tiempo, la probabilidad de votar por Johnny Araya fue un $12 \%$ mayor entre aquellos que pensaban que la economía había mejorado, con respecto a los que creían que había empeorado. Finalmente, las variables demográficas muestran un efecto significativo para algunos candidatos: Johnny Araya recibió los votos de las personas menos educadas, tal y como muestra el coeficiente de educación significativo y positivo para Solís, Villalta y Piza. Por su parte, la edad tuvo un impacto en esta elección, siendo Villalta el candidato beneficiado por el voto de los jóvenes.

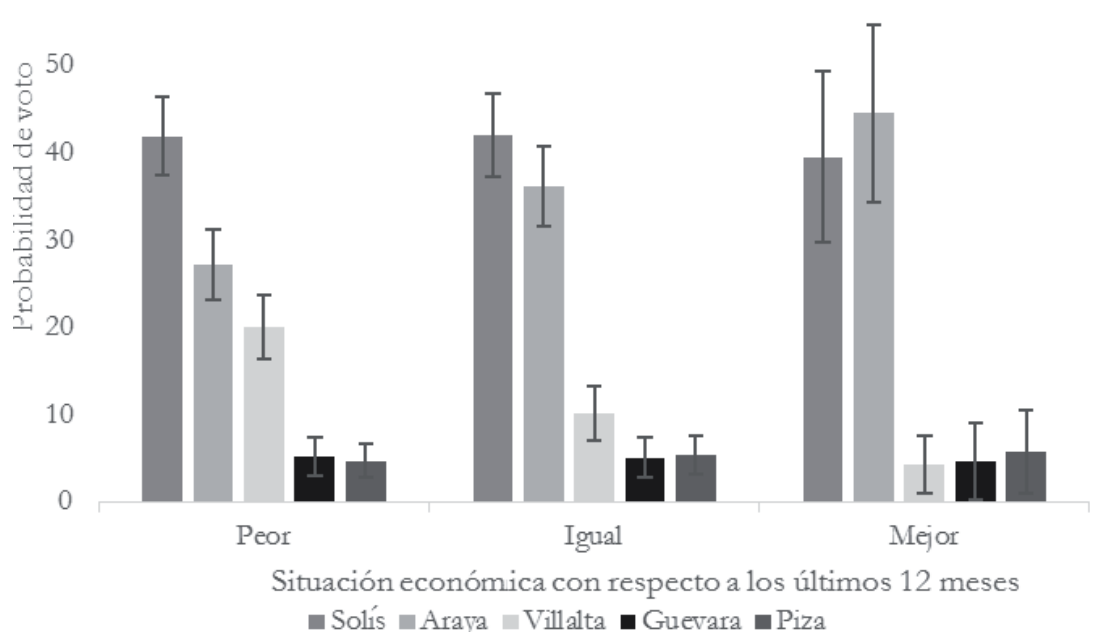

Fuente: Elaboración propia.

\section{IV.2. El Salvador (2014)}

Las elecciones de 1994 suelen fijarse como el origen del actual sistema de partidos salvadoreño. Desde entonces el sistema se ha caracterizado por el «pluralismo polarizado», poco fragmentado y con dos partidos dominantes -ambos actores del conflicto armado durante los años ochenta y muy distantes ideológicamente: la Alianza Republicana Nacionalista (ARENA) en la derecha, y el Frente Farabundo Martí de Liberación Nacional (FMLN), en la izquierda-. Los dos partidos se han disputado la victoria en comicios 
JUAN ANTONIO RODRÍGUEZ ZEPEDA Y PATRICIA OTERO FELIPE

PROXIMIDAD IDEOLÓGICA EN LAS ELECCIONES PRESIDENCIALES DE COSTA RICA,

EL SALVADOR Y HONDURAS

presidenciales, legislativos y municipales, seguidos a gran distancia por otras formaciones políticas. ARENA gobernó el país desde 1989 hasta el 2009, año en que se produjo la alternancia política en el Ejecutivo con la victoria del FMLN. Sin embargo, la proporcionalidad generada por el sistema electoral ocasionó, en el ámbito legislativo, una inferioridad numérica que se fue solventando con el apoyo negociado de los pequeños partidos. Una situación que no cambió en 2009, a pesar de la alternancia histórica que supuso la llegada del FMLN al Ejecutivo, puesto que al tener minoría en el órgano legislativo estuvo obligado a buscar aliados en la cámara, al igual que su predecesor (Artiga 2014).

\section{GRÁFICO V}

EvoluCiÓN DEL SISTEMA DE PARTIDOS DE El SALVADOR (1994-2015)20

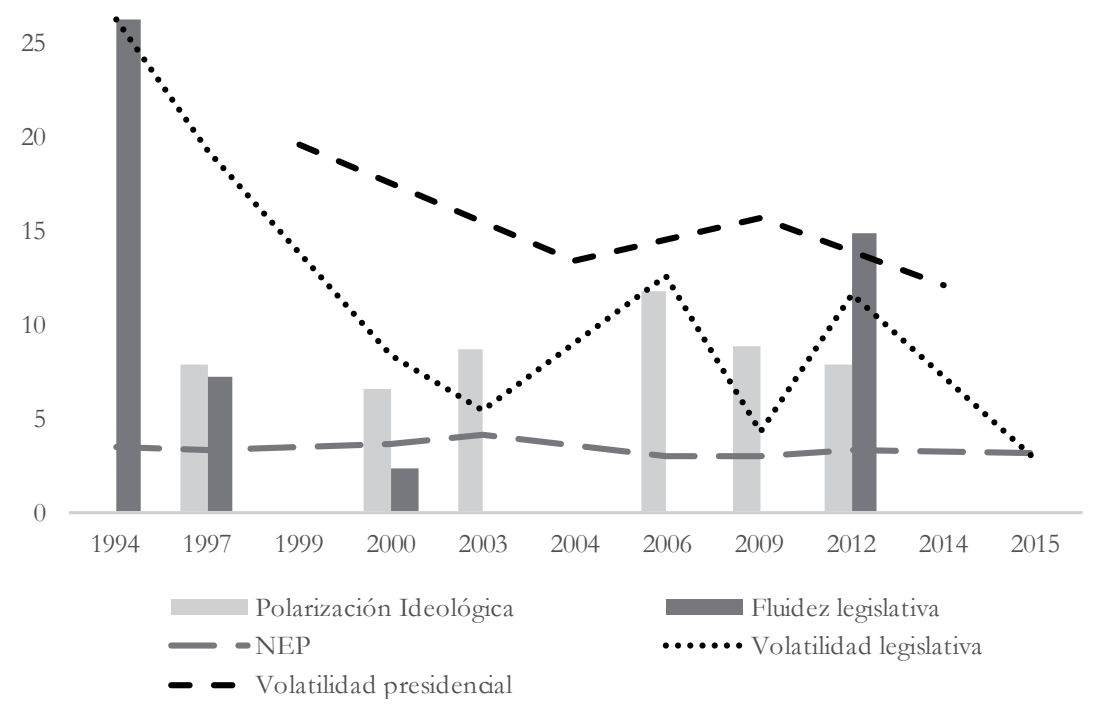

Fuente: Elaboración propia.

Desde sus inicios, el sistema de partidos ha dado muestras de gran estabilidad, tal y como muestran los índices de volatilidad, fragmentación o fluidez legislativa. Los salvadoreños no han modificado sustancialmente sus lealtades y con ello los patrones de voto. Sigue existiendo un nivel de identificación partidista por encima del promedio de la región y una destacada relevancia de la orientación ideológica en las preferencias electorales (Azpuru 2010; Otero y Rodríguez 2014). No obstante, hay dos aspectos que han alterado el contexto partidista recientemente. Primero, la crisis interna de ARENA,

20. En el Salvador el Poder Legislativo se renueva cada tres años y el ejecutivo cada cinco, por lo que la fecha de elecciones legislativas y presidenciales no necesariamente coincide. Los cálculos son de los autores. 
originada en 2009, que precipitó la salida de algunos de sus diputados del grupo legislativo. La consecuencia inmediata fue la creación en 2010 de la Gran Alianza por la Unidad Nacional (GANA), convertido actualmente en un actor fundamental de las negociaciones con el Ejecutivo. El segundo aspecto se refiere a la disminución de la polarización del sistema. El enfrentamiento entre las propuestas de ARENA y el FMLN durante los primeros años ha dado paso a un escenario de competencia más centrípeta en términos de propuestas sustantivas, especialmente desde que el FMLN asumió el Ejecutivo con Mauricio Funes (Azpuru 2010; Artiga 2014).

Las elecciones presidenciales tuvieron lugar el 2 de febrero de 2014 en un contexto económico favorable, pero con altos niveles de inseguridad y violencia. Por un lado, constituían una reválida al primer gobierno efemelinista, cuya gestión había despertado críticas entre los simpatizantes del Frente (Réserve 2016). Esta vez el FMLN escogió como candidato a un histórico del partido, vinculado con la administración anterior -Salvador Sánchez, vicepresidente con Funes y con amplia carrera política-. Por otro lado, la derecha se presentó dividida entre ARENA y la coalición electoral Movimiento Unidad, aunque con candidatos muy conocidos. Los areneros designaron para la presidencia a Norman Quijano, exalcalde de San Salvador y anteriormente diputado nacional en varias legislaturas. Antonio Saca, presidente del país entre 2004 y 2009, fue propuesto por la coalición que aglutinaba a GANA, Partido de la Conciliación Nacional (PCN) y Partido Demócrata Cristiano (PDC). Además de estos candidatos, hubo dos más, pertenecientes a pequeños partidos: René Rodríguez por el Partido Salvadoreño Progresista (PSP) y Óscar Lemus de Fraternidad Patriótica Salvadoreña (FPS). Fueron unas elecciones extraordinariamente reñidas y marcadas por la incertidumbre. De hecho, por segunda vez en la historia se celebró una segunda vuelta, al no alcanzar ningún candidato la mitad más uno de los votos -Sánchez logró un 48,9\%, Quijano un 38,9\% y Saca el 11,4\%-21. En estos comicios, celebrados el 9 de marzo, tan solo hubo una diferencia de 6.000 votos entre Sánchez y Quijano.

La Tabla II presenta los resultados del modelo PMM, en el que Sánchez es la opción base para realizar el contraste de los coeficientes. Al igual que en el caso costarricense, la distancia ideológica de los votantes con los candidatos tiene un efecto estadísticamente significativo y en el sentido esperado: la probabilidad de votar por un partido aumenta al disminuir la distancia ideológica entre el ciudadano y el candidato. Estos resultados, que concuerdan con los encontrados en investigaciones previas y que destacan la importancia de la ideología en el país (Aizpuru 2010), se observan claramente en los Gráficos VI y VII. En el primero de ellos presentamos las probabilidades de votar a los diferentes candidatos a partir de la variación de la distancia entre los votantes y el ganador -Salvador Sánchez-. Así, a mayor distancia ideológica entre la persona y este candidato, menor es la posibilidad de que el ciudadano le otorgue su voto. La magnitud de este efecto es considerable, con un rango de disminución entre el 4,1\% y el 7\%, y además se observa un patrón característico en los contextos polarizados: a mayor distancia ideológica entre los votantes y Sánchez, mayor es el incremento de probabilidad de voto que obtiene Quijano. Por su parte, el Gráfico VII contiene las probabilidades estimadas variando la distancia

21. Rodríguez (PSP) obtuvo un $0,4 \%$ y Morales (FPS) el 0,3\%. 
JUAN ANTONIO RODRÍGUEZ ZEPEDA Y PATRICIA OTERO FELIPE

PROXIMIDAD IDEOLÓGICA EN LAS ELECCIONES PRESIDENCIALES DE COSTA RICA,

EL SALVADOR Y HONDURAS

TABLA II

Modelo Probit Multinomial MiXto: El Salvador 2014

\begin{tabular}{l|l|c|c|c}
\hline \multicolumn{2}{c|}{} & COEFICIENTE & ERROR ESTÁNDAR & $\mathrm{P}>|\mathrm{z}|$ \\
\hline \multicolumn{2}{c|}{ DisTANCIA IDEOLÓGICA CON EL CANDIDATO } & $-0,235$ & 0,016 & 0,000 \\
\hline & QuIJANO / SÁNCHEZ & & & \\
\hline & Valoración económica retrospectiva & $-1,025$ & 0,133 & 0,000 \\
\hline & Mujer & 0,179 & 0,170 & 0,290 \\
\hline & Edad & $-0,002$ & 0,006 & 0,672 \\
\hline & Educación & 0,034 & 0,019 & 0,077 \\
\hline & Constante & $-1,202$ & 0,363 & 0,001 \\
\hline & \multicolumn{1}{|c|}{ SACA / SÁNCHEZ } & & & \\
\hline & Valoración económica retrospectiva & $-0,341$ & 0,164 & 0,038 \\
\hline & Mujer & $-0,099$ & 0,222 & 0,656 \\
\hline & Edad & $-0,016$ & 0,008 & 0,043 \\
\hline & Educación & 0,011 & 0,026 & 0,660 \\
\hline & Constante & 1,540 & 0,485 & 0,002 \\
\hline $\mathrm{N}$ & & & & \\
\hline Wald $\chi^{2}$ & & & & \\
\hline Prob $>\chi^{2}$ & & & & \\
\hline
\end{tabular}

Nota: Sánchez es la alternativa que normaliza la localización. Quijano es la alternativa que normaliza la escala.

Fuente: Elaboración propia.

ideológica con Norman Quijano. Aunque con una pauta similar al anterior, en este gráfico la penalización de los votantes a este candidato, conforme aumenta la distancia ideológica, es ligeramente menor (del 6,8\% al 2,9\%). Resulta muy interesante que las pérdidas en la probabilidad de voto por este candidato no pasan al otro candidato de la derecha (Saca), sino que son capitalizadas por Sánchez.

Los resultados anteriores confirman que la proximidad ideológica representa un factor explicativo del voto en las presidenciales del 2014, incluso considerando el efecto de las valoraciones económicas de los electores. En este sentido, una buena valoración de la situación económica del país (respecto a los últimos doce meses) supone una mayor probabilidad de votar por Sánchez (FMLN) con respecto a Saca. De igual modo, las personas que consideraban que la economía había empeorado tienen una mayor probabilidad de votar por Quijano con respecto a Saca. La relación descrita anteriormente se puede analizar de forma más clara en el Gráfico VIII. En este se observa que aquellos salvadoreños que valoraban de forma positiva el desempeño económico del país tienen una probabilidad estimada de votar por Sánchez cercana al 90\%, manteniendo todas las demás variables en sus valores medios. Dentro del grupo de los que respondieron que la situación económica 
34 JUAN ANTONIO RODRÍGUEZ ZEPEDA Y PATRICIA OTERO FELIPE

4 PROXIMIDAD IDEOLÓGICA EN LAS ELECCIONES PRESIDENCIALES DE COSTA RICA, EL SALVADOR Y HONDURAS

\section{GRÁFICO VI}

Distancia IDEOLÓGICA CON SALVADOR SÁNCHEZ y PROBABILIDAD DE VOTO

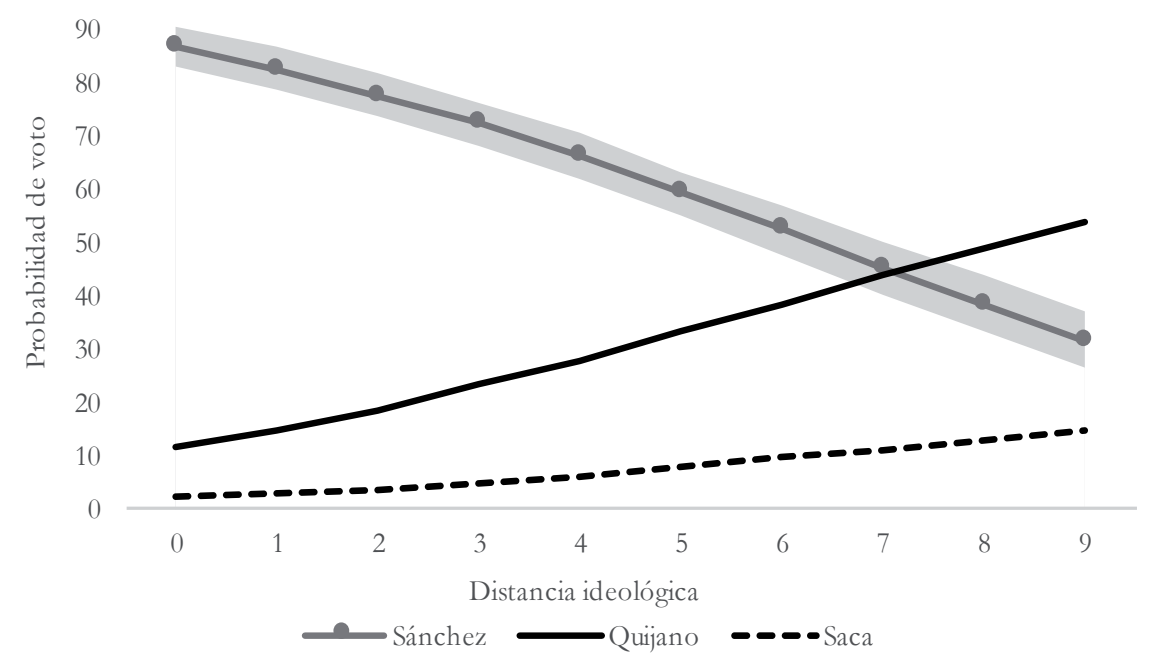

Fuente: Elaboración propia.

DistanCIA IDEOLÓGICA CON NORMAN QUIJANO Y PROBABILIDAD DE VOTO

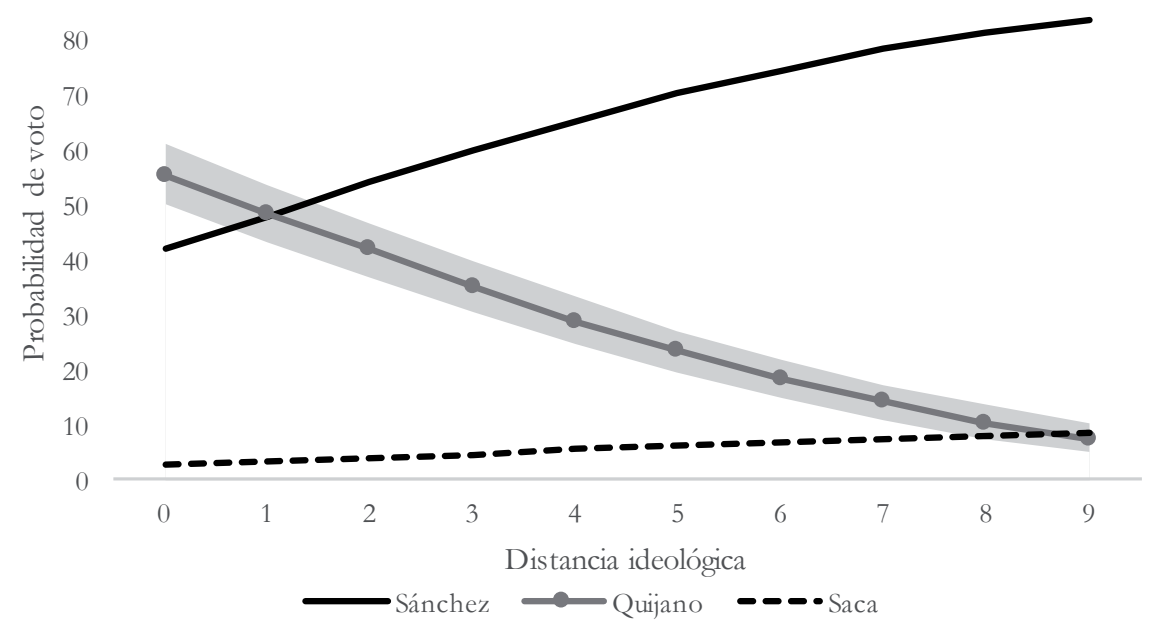

Fuente: Elaboración propia. 
era peor, la probabilidad de votar por Quijano y Sánchez es prácticamente la misma, lo que representa un aumento de un $40 \%$ para el primero. En cuanto a las variables demográficas, tan solo la edad de las personas tiene un efecto estadísticamente significativo: las personas más jóvenes prefirieron a Saca con respecto a Salvador Sánchez.

\section{GRÁFICO VIII \\ EL SALVADOR 2014: VALORACIÓN ECONÓMICA Y PROBABILIDAD DE VOTAR A LOS CANDIDATOS}

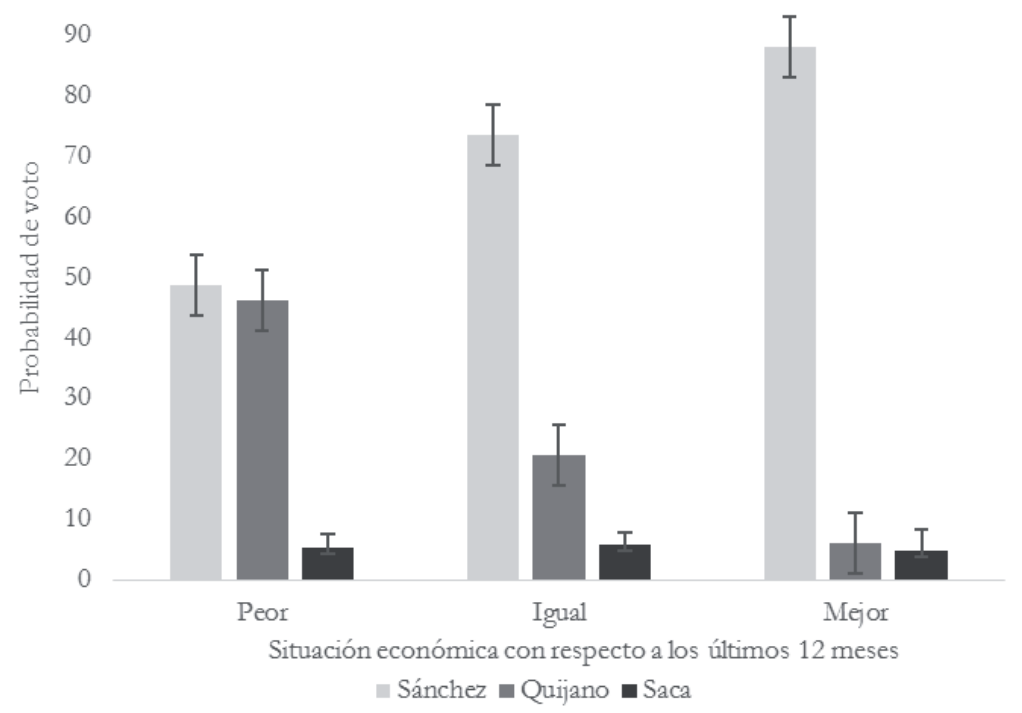

Fuente: Elaboración propia.

\section{IV.3. Honduras (2013)}

En Honduras la vida política ha girado en torno al Partido Nacional (PNH) y el Partido Liberal (PLH) desde su nacimiento, a principios del siglo XX. El protagonismo de ambos no disminuyó con la tardía democratización en los años ochenta o con la entrada de nuevas fuerzas políticas en el Poder Legislativo en los noventa. Así, se fue configurando un bipartidismo poco polarizado, escasamente volátil tanto en el ámbito legislativo como en el presidencial. La limitada diferenciación ideológica y programática entre sus partidos se puso de manifiesto en la continuidad por las políticas públicas aplicadas, a pesar de la alternancia regular en el Ejecutivo. La literatura ha destacado dos características que han contribuido a dicha estabilidad. Por un lado, la existencia de facciones internas, lo que aportó cierta flexibilidad, permitiendo la representación de diferentes intereses y sectores sociales, así como la «oxigenación» de liderazgos y la alternancia en las instancias de 
poder. Se trata de un aspecto que fue generando diferencias más claras al interior de los partidos que entre ellos y no pocos enfrentamientos internos. La segunda característica es la relevancia del clientelismo en el vínculo con el elector y el uso de las políticas gubernamentales para atraer el voto, de modo que en la explicación del comportamiento electoral de los hondureños la ideología no ha sido un factor relevante.

A pesar de la aparente solidez y estabilidad del sistema, los resultados electorales de la última década mostraban cierta desconexión de los hondureños con sus partidos. El aumento sostenido de la abstención, la dificultad de los partidos de atraer nuevos votantes y de movilizar a su voto duro ante una identidad partidista en declive, evidenciaban cierto descontento de la población hacía las instituciones representativas. En este sentido, el golpe de Estado y la siguiente crisis política que vivió el país en 2009, pusieron de manifiesto los déficits de representatividad del sistema y el agotamiento del mismo (Otero 2013). La consecuencia más visible fue el incremento de la polarización que se trasladó al ámbito político con la creación en 2012 de cuatro nuevos partidos, dos en la izquierda y dos en la derecha del espectro ideológico: Libertad y Refundación (LIBRE), el Frente Amplio Político Electoral en Resistencia (FAPER), el Partido Anticorrupción (PAC) y ALIANZA, respectivamente. Con esta nueva situación se llevaron a cabo las elecciones el domingo 26 de noviembre de 2013.

\section{GRÁFICO IX}

EvoluCión DEL SISTEMA DE PARTIDOS DE HONDURAS (1981-2013)22

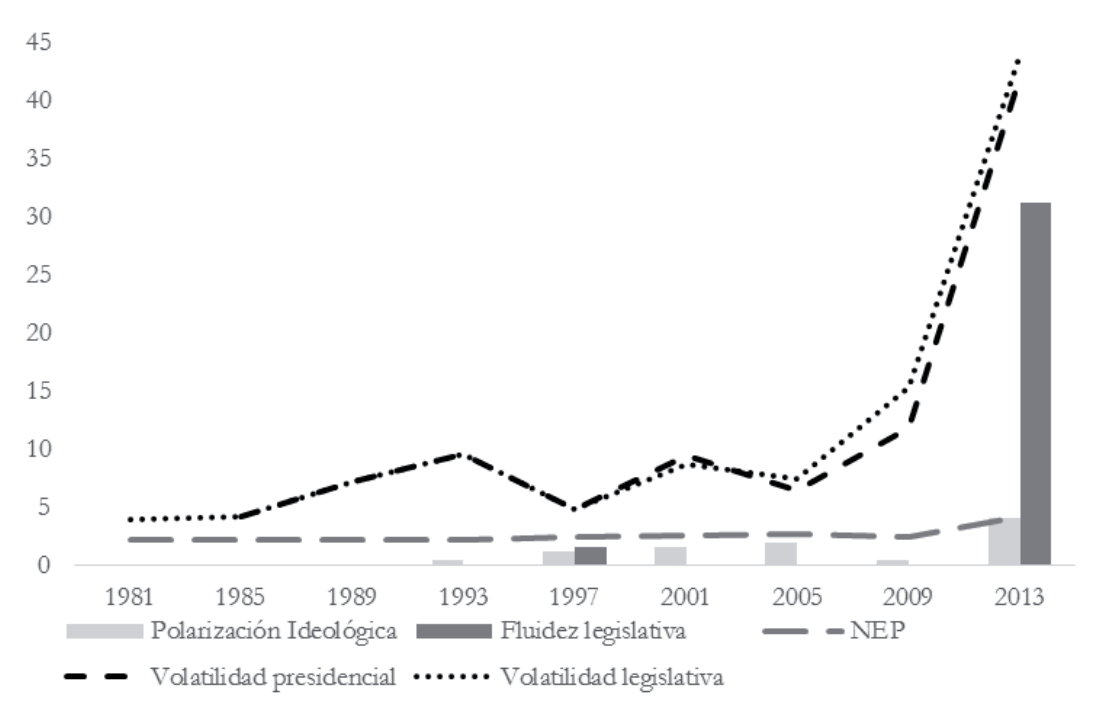

Fuente: Elaboración propia.

22. Los cálculos son de los autores. 
JUAN ANTONIO RODRÍGUEZ ZEPEDA Y PATRICIA OTERO FELIPE

PROXIMIDAD IDEOLÓGICA EN LAS ELECCIONES PRESIDENCIALES DE COSTA RICA,

EL SALVADOR Y HONDURAS

Precisamente, lo más relevante de los comicios fue el incremento de candidaturas presidenciales de muy diferente signo ideológico. Además, supuso la entrada de candidatos ajenos a la política tradicional, por lo que los hondureños pudieron escoger no solo entre opciones en la izquierda y en la derecha, sino entre candidatos «de partido» y políticos outsiders. Por el oficialismo se presentó Juan Orlando Hernández, anterior presidente del Congreso y representante de la facción más tradicional del partido. Sin embargo, la delicada situación del país con los habituales problemas económicos y sociales, junto con una baja popularidad del anterior presidente, marcaron una campaña fuertemente centrada en Hernández y un tanto alejada de los nacionalistas. Por el liberalismo se presentó Mauricio Villeda (PLH), que provenía del sector más conservador del partido, enfrentado con el expresidente Manuel Zelaya en la legislatura anterior. En cuanto a los nuevos candidatos destacaron dos: la representante de LIBRE, Xiomara Castro, esposa de Zelaya, cuya candidatura significó la presencia por primera vez de la izquierda política con posibilidades de triunfo electoral. Por el PAC, se presentó Salvador Nasralla, un periodista muy popular entre los hondureños ${ }^{23}$. Los resultados confirmaron el triunfo de Hernández en los comicios presidenciales con algo más del 36,8\% de los votos, pero también la debacle electoral de los liberales $(20,3 \%)$, que pasaron al tercer lugar por detrás de Castro $(28,7 \%)$. Nasralla se alzó con la cuarta posición $(13,4 \%)^{24}$.

La Tabla III contiene los resultados del modelo PMM para Honduras, en el que no se asume la IAI. En este caso el candidato que sirve de referencia es Hernández. De nuevo, la distancia ideológica de los electores respecto a los candidatos tiene un impacto en la probabilidad de voto en el sentido esperado - a mayor distancia, menor es dicha probabilidad-. Los Gráficos X y XI muestran las estimaciones a partir de los coeficientes del modelo. En el primero de ellos se puede observar que la probabilidad de votar por Hernández disminuye 20 puntos porcentuales en el rango posible de esta variable -de cero a nueve puntos-. Aunque el modelo hace una predicción muy alta de votar por este candidato, a pesar de una gran distancia ideológica, la disminución mencionada muestra que los ciudadanos sí tenían menores posibilidades de favorecer a Hernández cuando percibían una diferencia importante con su posición ideológica. En este escenario es Castro quien se beneficia en mayor medida de esta disminución y no el candidato liberal (Villeda), como a priori podía suponerse. La primera capitaliza un $9 \%$ de dicho descenso, mientras que el segundo un $5 \%$.

Por otro lado, la variación en las probabilidades estimadas al aumentar la distancia ideológica entre los votantes y la candidata de LIBRE presenta un patrón muy interesante (Gráfico XI). En este caso la tasa de disminución de voto por Castro tiene un patrón descendente (del 3,63\% al 1,76\%), pero se observa que es Mauricio Villeda quien más aumenta proporcionalmente su probabilidad de ser elegido al disminuir dicha probabilidad para Xiomara Castro. En otras palabras, el candidato del Partido Liberal parece

23. A estos hay que añadir los candidatos de los pequeños partidos, Jorge Aguilar, Orle Solís, Romeo Vásquez y Andrés Pavón, por PINU, PDC, ALIANZA y PUD-FAPER respectivamente, que apenas sumaron un $1 \%$ de los votos.

24. A diferencia de Costa Rica y El Salvador, en Honduras el candidato ganador se establece por mayoría relativa. No hay una segunda vuelta. 
JUAN ANTONIO RODRÍGUEZ ZEPEDA Y PATRICIA OTERO FELIPE PROXIMIDAD IDEOLÓGICA EN LAS ELECCIONES PRESIDENCIALES DE COSTA RICA, EL SALVADOR Y HONDURAS

TABLA III

Modelo Probit Multinomial Mixto: Honduras 2013

\begin{tabular}{|c|c|c|c|c|}
\hline & & COEFICIENTE & ERROR ESTÁNDAR & $P>|z|$ \\
\hline DisTANC & IA IDEOLÓGICA CON EL CANDIDATO & $-0,081$ & 0,023 & 0,000 \\
\hline & CASTRO / HERNÁNDEZ & & & \\
\hline & Valoración económica retrospectiva & $-0,639$ & 0,113 & 0,000 \\
\hline & Mujer & $-0,434$ & 0,132 & 0,001 \\
\hline & Edad & 0,007 & 0,005 & 0,219 \\
\hline & Educación & 0,075 & 0,017 & 0,000 \\
\hline & Urbano & 0,406 & 0,151 & 0,007 \\
\hline & Constante & $-1,578$ & 0,316 & 0,000 \\
\hline & VILLEDA / HERNÁNDEZ & & & \\
\hline & Valoración económica retrospectiva & $-0,529$ & 0,167 & 0,002 \\
\hline & Mujer & $-0,482$ & 0,183 & 0,008 \\
\hline & Edad & 0,011 & 0,007 & 0,118 \\
\hline & Educación & 0,085 & 0,028 & 0,003 \\
\hline & Urbano & 0,593 & 0,228 & 0,009 \\
\hline & Constante & $-2,237$ & 0,815 & 0,006 \\
\hline & NASRALLA / HERNÁNDEZ & & & \\
\hline & Valoración económica retrospectiva & $-0,459$ & 0,151 & 0,002 \\
\hline & Mujer & $-0,458$ & 0,166 & 0,006 \\
\hline & Edad & $-0,004$ & 0,007 & 0,581 \\
\hline & Educación & 0,074 & 0,023 & 0,002 \\
\hline & Urbano & 0,584 & 0,212 & 0,006 \\
\hline & Constante & $-1,400$ & 0,474 & 0,003 \\
\hline $\mathrm{N}$ & 906 & & & \\
\hline Wald $\chi^{2}$ & 97,71 & & & \\
\hline Prob $>\chi^{2}$ & 0,000 & & & \\
\hline
\end{tabular}

Nota: Hernández es la alternativa que normaliza la localización. Castro es la alternativa que normaliza la escala. Fuente: Elaboración propia.

ser la opción que eligieron los votantes que consideraban a la abanderada de LIBRE como una candidata muy radical. Sin embargo, Castro sí atrajo electores distanciados ideológicamente de Hernández, pese al habitual trasvase de votos entre los dos partidos tradicionales. Unos elementos que marcan la excepcionalidad de estos comicios presidenciales. 
JUAN ANTONIO RODRÍGUEZ ZEPEDA Y PATRICIA OTERO FELIPE

PROXIMIDAD IDEOLÓGICA EN LAS ELECCIONES PRESIDENCIALES DE COSTA RICA,

EL SALVADOR Y HONDURAS

GRÁFICO X

DistanCIA IDEOLÓGICA CON JUAN ORLANDO HERNÁNDEZ Y PROBABILIDAD DE VOTO

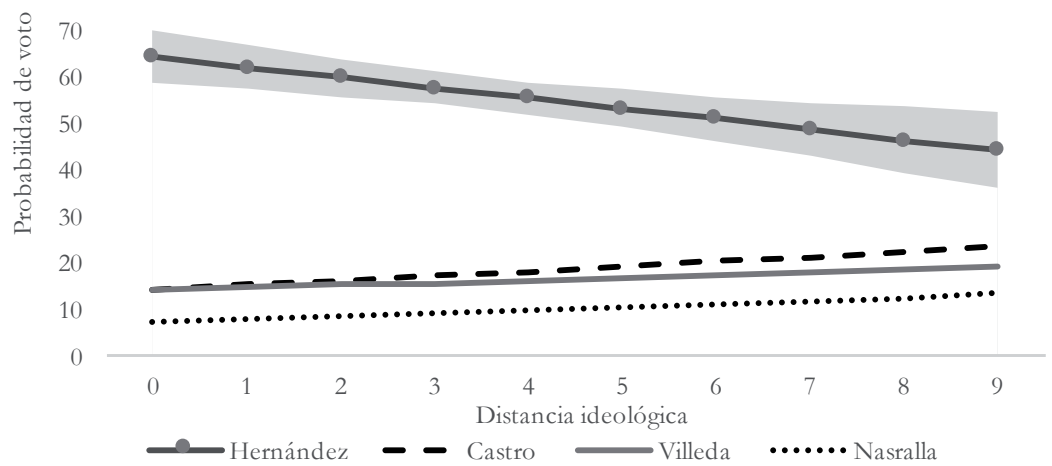

Fuente: Elaboración propia.

GRÁFICO XI

DisTANCIA IDEOLÓGICA CON XIOMARA CASTRO Y PROBABILIDAD DE VOTO

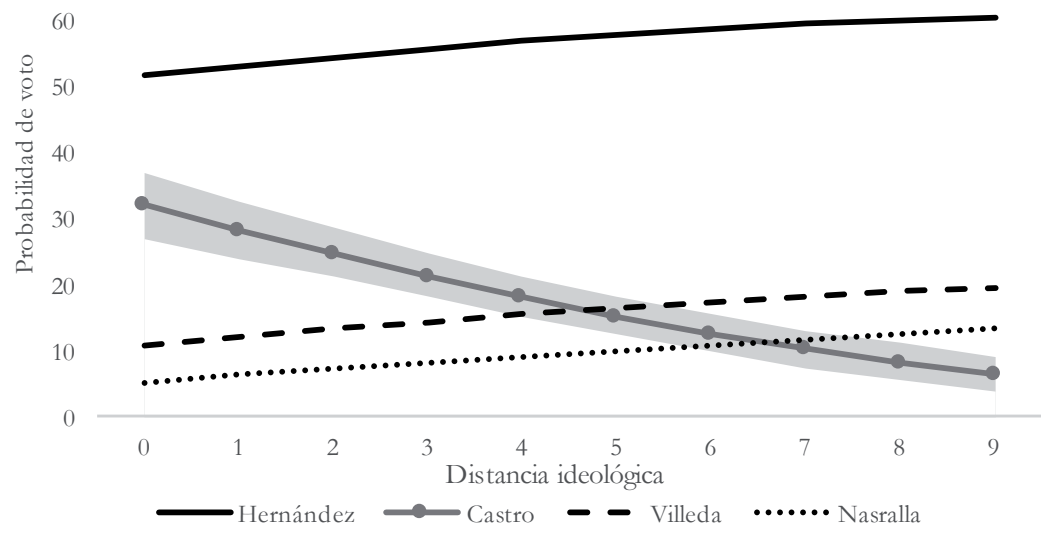

Fuente: Elaboración propia.

En cuanto a la evaluación de la situación económica, se trata de un factor que sí fue significativo en la elección presidencial. El coeficiente es significativo y en el sentido esperado (negativo) para todos los candidatos. Al estimar las probabilidades de voto se observa que el candidato del Partido Nacional se benefició electoralmente de las personas que consideraron que la situación económica había mejorado en el último año. La diferencia de probabilidad de votar a este candidato, entre los que respondieron que la situación económica era peor y los que opinaron lo contrario, es del 30\% (Gráfico XII). 
Además, los resultados del modelo muestran que la probabilidad de votar a los candidatos de oposición es mayor entre los hombres, así como las personas con mayor nivel educativo y que viven en zonas urbanas. Unos resultados que confirman los hallazgos de estudios previos sobre las características del electorado del PNH, que lo diferencia del resto de partidos (Menéndez 2014).
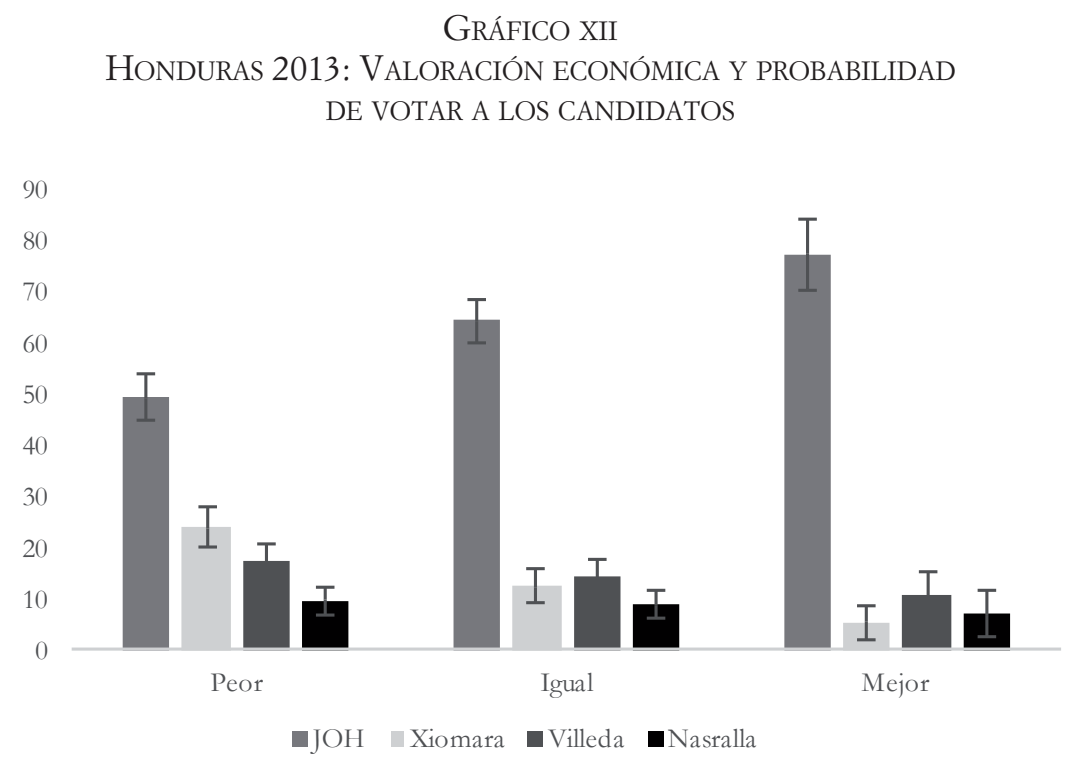

Fuente: Elaboración propia.

\section{Conclusiones}

¿Qué elementos explican el voto de los comicios presidenciales en los países latinoamericanos? La respuesta a esta cuestión sigue generando abundante literatura y muchas explicaciones. La región cuenta con buenos ejemplos de sistemas de partidos fragmentados, fluidos y volátiles, donde la identidad partidista es débil y las prácticas clientelares relativamente frecuentes. No es de extrañar que los factores a corto plazo y contextuales, como el estado de la economía o la imagen de un candidato, hayan constituido el grueso del análisis del comportamiento electoral, dejando al elemento ideológico en un segundo plano. En este sentido, son muy pocos los estudios que han analizado el papel que la proximidad ideológica tiene en el voto y, cuando se ha hecho, se ha estimado a través de métodos indirectos, por lo que la evidencia empírica no es concluyente. 
JUAN ANTONIO RODRÍGUEZ ZEPEDA Y PATRICIA OTERO FELIPE

PROXIMIDAD IDEOLÓGICA EN LAS ELECCIONES PRESIDENCIALES DE COSTA RICA,

EL SALVADOR Y HONDURAS

En este trabajo hemos abordado el análisis del voto de proximidad con métodos estadísticos adecuados, con el objetivo de modelar los procesos de decisiones electorales individuales a través de modelos PMM que apenas han sido utilizados en los estudios electorales de la región. Esta aproximación permite tener variables inherentes a las opciones de decisión y comprobar si el factor de cercanía ideológica con el candidato presidencial tiene efecto. Con este objetivo, hemos comprobado la incidencia del voto por proximidad en las elecciones presidenciales más recientes de Costa Rica, El Salvador y Honduras. Países que están experimentando una reconfiguración en los últimos años, pero comparten algunos rasgos del sistema de partidos, en cuanto a su tradicional estabilidad, volatilidad limitada y fragmentación, así como su baja fluidez y presencia de outsiders, lo cual podría facilitar el voto por proximidad, tal y como ha esbozado la literatura. Así, el grado de polarización ideológica relativamente alto en El Salvador, y limitado en Costa Rica y Honduras, parece experimentar variaciones. De igual modo, el papel de la ideología en la atracción de electores próximos se muestra significativo en El Salvador y reducido en los partidos tradicionales de Costa Rica y Honduras. Asimismo, la presencia de candidatos externos a la vida partidista y exitosos en las elecciones analizadas ha modificado sustancialmente los patrones de voto, tal y como hemos visto en Costa Rica y Honduras.

Los hallazgos del análisis desafían el saber convencional y apuntan a que la proximidad ideológica cuenta en el voto presidencial en los tres países, incluidos aquellos en los que se presume la incidencia del vínculo clientelar y personalista o la relevancia de factores contextuales en el comportamiento electoral. Los datos muestran que la cercanía ideológica fue un factor relevante en el voto de las elecciones presidenciales de Costa Rica, procesos en los que por primera vez ganó un candidato no tradicional. El Salvador exhibe unos resultados más contundentes, que confirman los hallazgos de los trabajos previos que han señalado el peso de la ideología en sus elecciones, incluso controlando la valoración del estado de la economía. De igual manera, los comicios hondureños plantean un punto de inflexión en el comportamiento electoral: en un contexto polarizado, con la presencia por primera vez en décadas de candidaturas distantes ideológicamente, se observa que la proximidad afectó al voto y modificó los habituales trasvases de electores entre los dos partidos tradicionales.

De este modo, el trabajo realiza aportaciones a los estudios sobre la proximidad ideológica en general, así como al conocimiento de los casos centroamericanos en particular. Por un lado, ofrece una perspectiva metodológica distinta para abordar la explicación de elecciones presidenciales, permitiendo mostrar su incidencia en contextos partidistas diferentes. Por otro, proporciona evidencia del papel que tiene la cercanía ideológica en las elecciones presidenciales de países poco estudiados, ampliando el tipo de explicaciones ofrecidas en la literatura. En este sentido, el desarrollo empírico de este fenómeno en trabajos posteriores, más allá de las variaciones intrarregionales, puede completarse con el análisis de elecciones legislativas o explorando la perspectiva individual, mostrando, por ejemplo, el perfil de los electores que deciden su voto de acuerdo a la proximidad ideológica. 


\section{BIBLIOGRAFÍA}

AlCÁNTARA, Manuel. ¿Instituciones o máquinas ideológicas? Origen, programa y organización de los partidos latinoamericanos. Barcelona: ICPS, 2004.

Álvarez, Michael y NAGLER, Jonathan. When Politics and Models Collide: Estimating Models of Multiparty Elections. American Journal of Political Science, 1998, vol. 42 (1): 55-96.

ArTigA, Álvaro. Los partidos políticos frente a la plena capacidad de opción. Estudios Centroamericanos, 2014, vol. 740: 15-43.

AtKeSON, Lonna Rae. «Sure, I Voted for the Winner!» Overreport of the Primary Vote for the Party Nominee in the National Election Studies. Political Behavior, 1999, vol. 21 (3): 197-215.

AzPuRu, Dinorah. The Salience of Ideology: Fifteen Years of Presidential Elections in El Salvador. Latin American Politics and Society, 2010, vol. 52 (2): 103-138.

BAKER, Andy y GreEne, Kenneth. The Latin American Left's Mandate: Free-Market Policies and Issue Voting in New Democracies. World Politics, 2011, vol. 63 (1): 43-77.

BaKer, Andy y Greene, Kenneth. Positional Issue Voting in Latin America. En CarLin, Ryan; Singer, Matthew y ZeCHMEISTER, Elizabeth (eds.). The Latin American Voter. Ann Arbor: University of Michigan Press, 2015: 173-194.

Boscán, Guillermo. Voto y competición electoral en América Latina. Tesis doctoral. Salamanca: Universidad de Salamanca, 2016.

Colomer, Josep M. y Escatel, Luis E. La dimensión izquierda-derecha en América Latina. Desarrollo Económico, 2005, vol. 45 (177): 123-136.

Dow, J. K. y EnDERSBY, W. Multinomial Probit and Multinomial Logit: A Comparison of Choice Models for Voting Research. Electoral studies, 2004, vol. 23 (1): 107-122.

Downs, Anthony. An Economic Theory of Democracy. Nueva York: Harper and Row, 1957.

EnElow, James y Hinich, Melvin. The Spatial Theory of Voting. An Introduction. Nueva York: Cambridge University Press, 1984.

FAZEKAS, Zoltan y Zsombor, Meder. Proximity and Directional Theory Compared: Taking Discriminant Positions Seriously in Multi-party Systems. Electoral Studies, 2013, vol. 32 (4): 693-707.

Grofman, Bernard. The Neglected Role of the Status Quo in Models of Issue Voting. Journal of Politics, 1985, vol. 47: 230-237.

Hotelling, Harold. Stability in Competition. Economic Journal, 1929, vol. 39 (153): 41-57.

IVERSEN, Torven. The Logics of Electoral Politics: Spatial, Directional, and Mobilization Effects. Comparative Political Studies, 1994, vol. 27 (1): 155-189.

KedAR, Orit. Voting for Policy not for Parties: How Voters Compensate for Power Sharing. Cambridge: Cambridge University Press, 2009.

Key JR., V. O. The Responsible Electorate: Rationality in Presidential Voting 1936-1960. Cambridge: Harvard University Press, 1966.

KINDER, Donald D. y KIEWIET, D. Roderick. Economic Discontent and Political Behavior: The Role of Personal Grievances and Collective Economic Judgments in Congressional Voting. American Journal of Political Science, 1979, vol. 23 (3): 495-527.

LACY, Dean y PAOLINO, Philip. Testing Proximity versus Directional Voting using Experiments. Electoral Studies, 2010, vol. 29 (3): 460-471.

LACHAT, Romain. The Impact of Party Polarization on Ideological Voting. Electoral Studies, 2008, 27 (4): 687-698 
JUAN ANTONIO RODRÍGUEZ ZEPEDA Y PATRICIA OTERO FELIPE

PROXIMIDAD IDEOLÓGICA EN LAS ELECCIONES PRESIDENCIALES DE COSTA RICA,

EL SALVADOR Y HONDURAS

LAPOP. Barómetro de las Américas 2014. Proyecto de Opinión Pública en América Latina. Universidad de Vanderbilt. Disponible en: www.vanderbilt.edu/lapop-espanol.

LEWIS, Jeffrey y KING, Gary. No Evidence on Directional vs. Proximity Voting. Political Analysis, 1999, vol. 8: 21-33.

LONG, J. S. y FREESE, J. Regression models for categorical dependent variables using Stata. College Station: Stata Press, 2014.

LunA, Juan Pablo. Segmented Representation. Political Party Strategies in Unequal Democracies. Oxford: Oxford University Press, 2014.

LunA, Juan Pablo y ZechmeIster, Elizabeth. Political Representation in Latin America. A Study of Elite-Mass Congruence in Nine Countries. Comparative Political Studies, 2005, vol. 38 (4): 388-416.

MaINWARING, Scott y TORCAL, Mariano. La institucionalización de los sistemas de partidos y la teoría del sistema partidista después de la tercera ola democratizadora. América Latina Hoy, 2005, vol. 41: 141-173.

MenÉndeZ, Carlos. Honduras. Elecciones 2013: compra de votos y democracia. Honduras: Centro de Estudios y Documentación de Honduras, 2014.

Otero Felipe, Patricia. El sistema de partidos de Honduras tras la crisis política del 2009: ¿el fin del bipartidismo? Colombia Internacional, 2013, vol. 79: 249-287.

Otero Felipe, Patricia y Rodríguez ZePeda, Juan Antonio. Vínculos ideológicos y rendimiento electoral en América Latina. Política y Gobierno, 2014, vol. 21 (1): 159-200.

PARDOS-PRAdO, Sergi y Dinas, Elías. Systemic Polarization and Spatial Voting. European Journal of Political Research, 2010, 49 (6): 759-786.

Pela. Base de datos del Proyecto Elites Parlamentarias de América Latina. Universidad de Salamanca. Disponible en: americo.usal.es/oir/elites/bases_de_datos-htm.

Quinn, Kevin M.; Martin, Andrew, D., y Whitford, Andrew B. Voter Choice in Multi-Party Democracies: A Test of Competing Theories and Models. American Journal of Political Science, 1999, vol. 43: 1231-1247.

Rabinowitz, G. y McDonald, S. E. A Directional Theory of Issue Voting. American Political Science Review, 1989, vol. 83: 93-121.

RÉSERVE, Roody. El Salvador: Un año político y social convulso. Revista de Ciencia Política, 2016, vol. 36 (1): 177-194.

Rosas, Guillermo. The Ideological Organization of Latin American Legislative Parties: An Empirical Analysis of Elite Policy Preferences. Comparative Political Studies, 2005, vol. 38 (7): 824-849.

Ruiz Rodríguez, Leticia y Otero FeliPe, Patricia. Indicadores de Partidos y Sistemas de Partidos. Madrid: CIS, 2013.

SÁNCHEZ, Fernando. Cambio en la dinámica electoral en Costa Rica: un caso de Desalineamiento. América Latina Hoy, 2003, vol. 35: 115-146.

SELigson, Mitchell A. The Rise of Populism and the Left in Latin America. Journal of Democracy, 2007, vol. 18 (3): 81-95.

Thurner, Paul W. The Empirical Application of the Spatial Theory of Voting in Multiparty Systems with Random Utility Models. Electoral Studies, 2000, vol. 19: 493-517.

Tomz, Michael y Van Houweling, Robert P. Candidate Positioning and Voter Choice. American Political Science Review, 2008, vol. 102 (3): 303-318.

TraIn, Kenneth E. Discrete choice methods with simulation. Nueva York: Cambridge University Press, 2009. 
JUAN ANTONIO RODRÍGUEZ ZEPEDA Y PATRICIA OTERO FELIPE PROXIMIDAD IDEOLÓGICA EN LAS ELECCIONES PRESIDENCIALES DE COSTA RICA, EL SALVADOR Y HONDURAS

TREMiÑo, Ilka. El PAC al poder: Elecciones 2014 y los principales cambios en el sistema político costarricense. Península, 2016, vol. 11 (1): 103-126.

Westholm, Anders. Distance versus Direction: The Illusory Defeat of the Proximity Theory of Electoral Choice. American Political Science Association, 1997, vol. 91 (4): 865-883.

Zoco, Edurne. Legislators' Positions and Party System Competition in Central America: A Comparative Analysis. Party Politics, 2006, vol. 12 (2): 257-280.

\section{APÉNDICE}

\section{TABLA I}

Posiciones IDEOLÓGICAS DE LOS CANDIDATOS PRESIDENCIALES

\begin{tabular}{l|c}
\hline \multicolumn{1}{c|}{ COSTA RicA } & POSICIÓN IDEOLÓGICA \\
\hline Luis Guillermo Solis (PAC) & 5,11 \\
\hline Johnny Araya (PLN) & 7,07 \\
\hline Otto Guevara (ML) & 9,24 \\
\hline José María Villalta (FA) & 2,36 \\
\hline Rodolfo Piza (PUSC) & 7,18 \\
\hline \multicolumn{1}{c|}{ EL SALVADOR } & 9,25 \\
\hline Norman Quiijano (ARENA) & 1,54 \\
\hline Salvador Sánchez Cerén (FMLN) & 6,52 \\
\hline Antonio Saca (GANA) & 8,67 \\
\hline Juan Orlando Hernández (PNH) & 2,27 \\
\hline Xiomara Castro de Zelaya (LIBRE) & 7,76 \\
\hline Mauricio Villeda (PLN) & 5,83 \\
\hline Salvador Nasralla (PAC) & \\
\hline Nota La poscín de los car & \\
\hline
\end{tabular}

Nota: La posición de los candidatos corresponde a la media de la ubicación que dieron a los candidatos los diputados entrevistados en las encuestas de PELA en cada uno de los países.

Fuente: Elaboración propia a partir de los datos de PELA. 
JUAN ANTONIO RODRÍGUEZ ZEPEDA Y PATRICIA OTERO FELIPE PROXIMIDAD IDEOLÓGICA EN LAS ELECCIONES PRESIDENCIALES DE COSTA RICA,

EL SALVADOR Y HONDURAS

TABLA II

DESCRIPTIVOS DE LAS VARIABLES INCLUIDAS EN EL ANÁLISIS

\begin{tabular}{l|c|c|c|c}
\hline \multicolumn{1}{c|}{ COSTA RICA } & MEDIA & DESV. ESTÁNDAR & MíNIMO & MÁXIMO \\
\hline Distancia ideológica & & & & \\
\hline Evaluación económica retrospectiva & 2,86 & 2,00 & 0,07 & 8,24 \\
\hline Sexo & $-0,54$ & 0,58 & -1 & 1 \\
\hline Edad & 0,50 & 0,50 & 0 & 1 \\
\hline Educación EL SALVADOR & 43,15 & 16,61 & 18 & 90 \\
\hline & 9,22 & 4,12 & 0 & 18 \\
\hline Distancia ideológica & & & & \\
\hline Evaluación económica retrospectiva & $-0,27$ & 0,71 & -1 & 1 \\
\hline Sexo & 0,51 & 0,50 & 0 & 1 \\
\hline Edad & 41,21 & 16,19 & 19 & 90 \\
\hline Educación & 8,90 & 4,90 & 0 & 18 \\
\hline \multicolumn{1}{c|}{ HonduRAS } & & & & \\
\hline Distancia ideológica & 3,22 & 2,08 & 0,17 & 7,73 \\
\hline Evaluación económica retrospectiva & $-0,49$ & 0,63 & -1 & 1 \\
\hline Sexo & 0,49 & 0,50 & 0 & 1 \\
\hline Edad & 40,83 & 14,81 & 19 & 88 \\
\hline Educación & 7,50 & 4,48 & 0 & 18 \\
\hline Urbano/rural & 0,53 & 0,50 & 0 & 1 \\
\hline & & & &
\end{tabular}

Fuente: Elaboración propia a partir de los datos de LAPOP. 
